\title{
Socio Economic Impact Assessment of Pre-harvest Sugarcane Burning: Empirical Data Around Wonji/Shoa and Matahara Sugar Factories
}

\author{
Gutema Bati Fedi ${ }^{1 *}$, Birhanu Hailu Fanta ${ }^{2}$ and Tizazu H/Mariam ${ }^{2}$ \\ 1.Socioeconomics Research Program of Research and Development Main Center at Ethiopian Sugar \\ Corporation, P.O. Box 15, Adama/Wonji, Ethiopia \\ 2.Ethiopian Environment and Forest Research Institute at Central Ethiopia Research Center, Finfinne/Addis \\ Ababa, Ethiopia
}

\begin{abstract}
In Ethiopia, the area of sugarcane is rising rapidly in response to increased sugar demand for human consumption. Despite considerable diversity in production systems and contexts, sugarcane is particularly high impact crop with significant positive and negative environmental and socio economic influences. Depending on a systematic review of scientific evidence combined with data that was collected through household interviews, key informant interviews, focus group discussions, direct observation and field notes of the researcher as well as secondary data from various sources to complement the primary data, the present study assess the socio economic and environmental impacts resulting from pre-harvest burning of cane in Wonji/Shoa and Metahara sugarcane estates. The results of study Show that the pre-harvest burning of cane harvesting practices have negative impacts on local economy in terms of human health (both local communities and sugarcane workers) resulting from smokes and dust particles. Moreover, the pre-harvest burning sugarcane practices have negative environmental effects as demonstrated by clearing of vegetation cover, depletion of water resources and soil degradation. On the other hand, sugarcane trash resources can be used for animals' feed and alternative energy sources like sugarcane briquette charcoal. Our findings then will help to guide sugar industries and policy makers with new insights/strategies in understanding the situated environmental and social impacts associated with alternative sugarcane harvesting system by using green harvesting technologies (either manual or mechanical) and at the same time opening job opportunity to the local communities by utilization of trash as animals feed, energy source and compost. Finally, recommendations have been provided in order to address the socio-economic and environmental effects on local communities and sugarcane workers and air quality management.
\end{abstract}

Keywords: Pre-harvest sugarcane burning, Wonji/Shoa, Metahara, impact

DOI: $10.7176 /$ RHSS/11-19-04

Publication date:October $31^{\text {st }} 2021$

\section{Introduction}

In the production of sugar from sugarcane, pre-harvest open burning of trash in commercial sugarcane fields was carried out in Ethiopia and others sugar producing countries. The burning practices was generally performed to facilitate and optimizes manual crop cutting/increase harvesting efficiency (Figueiredo and La Scala 2011) by removing most of the residues (like dead, dry and fresh leaves) and by eliminating venomous animals (like insects/snakes) (Thorburn et al. 2001) and reducing water content and; thereby, increasing sugar content (Marcos et al 2000). However, the emissions from biomass burning practices of sugarcane trash is responsible for environmental, social and economical impacts that contribute significantly the emission of large quantities of pollutants that contributes to adverse effects on the health of workers and local populations (Ribeiro 2008) and exposes sugarcane cutting workers to several risks responsible for health problems (like respiratory, renal, cardiovascular, osteomuscular, ocular, and dermatological) and have significantly high mortality rate of workers employed due to illnesses (Leite et al 2018); to cause a reduction in air quality and have negative impacts on the potential energy value of the plant (Cançado et al 2006)

To improve these human and environmental problems, Global sugar markets, sugar producer and supplier countries have signed the agreement called "green protocol" to stop burning of sugarcane fields. An agreement state that all developed countries (at the end of 2017) and developing countries (at a period between 2017 and 2021) should stop pre-harvest burning of sugarcane. However, Brazil and other developed countries had already stopped almost $100 \%$ and had been starting green harvesting technologies or mechanical harvesting. Many plantations that choose manual and/or mechanized harvesting without burning, increase productivity and income generation; reduce environmental harm and increase cogeneration potential.

In Ethiopia, to boost the national sugar production to satisfy the local demand of sugar and to export sugar at international market, the government is aggressively constructing new sugar factories and refurbishing the existing ones. Accordingly, greater attention is given to the expansion of land development for sugarcane cultivation. However, as the volume of sugarcane yield increases the volume of emission from pre-harvest burning of 
sugarcane trash has its own impacts such as air pollution, loss of biodiversity, resource degradation and loss of soil fertility.

Ethiopia and other developing countries had continued conducting business as usual. To our knowledge, there are no studied documents on impacts of pre-harvest burning of sugarcane in Ethiopia that fill the policy gaps on effective implementation of socioeconomic impacts of the mentioned problem. Thus, this study was initiated on assessing the status of socio economic impacts of pre-harvest burning of sugarcane in Ethiopian sugar factories; about the efforts needed to create public policies that change the existing harvesting system into green harvesting technology and the utilization of burning trash to others economic option (like energy source and animals' feed to the communities around the factories) when the factories practice green sugarcane harvesting system that are important issues.

\section{Materials and Methods \\ Study areas}

The study was conducted at Wonji/Shoa Sugar Factory (WSSF) and Matahara Sugar Factory (MSF). Wonji/Shoa Sugar Factory is state owned plant that is located in The Oromia Regional State. It lies downstream of the "Koka Dam" in the central rift valley of Ethiopia in the upper reaches of Awash River basin, about $100 \mathrm{~km}$ southeast of Finfinnee/Addis Ababa and about $10 \mathrm{~km}$ south of Adama Town. It is located at $8^{0} 21^{\prime}$ to $8^{0} 29^{\prime} \mathrm{N}$ and $39^{\circ} 12^{\prime}$ to $39^{0} 18^{\prime} \mathrm{E}$ with an altitude of 1550 meters above sea level, annual rainfall of $830 \mathrm{~mm}$, and means air temperature of $20.8 \mathrm{C}^{0}$ and relative humidity of $56 \%$.

Metahara Sugar Estate has a semi-arid climatic characteristic; it is located at about $200 \mathrm{~km}$ southeast of Finfinnee /Addis Ababa, it is located in the Rift Valley of Ethiopia at latitude of $8^{\circ} 53^{\prime} \mathrm{N}$ and longitude of $39^{\circ} 52^{\prime}$ $\mathrm{E}$ with an elevation of 950 meters above sea level. The area has a mean annual maximum temperature of $32.6{ }^{\circ} \mathrm{C}$ and a mean annual minimum temperature of $17.5{ }^{\circ} \mathrm{C}$. It has a mean annual rainfall of $554 \mathrm{~mm}$.

\section{Data sources and collection methods}

The current study used both primary and secondary data. Primary survey data were collected from WSSF, MSF and nearby communities through, pre-tested and necessary modifications were made before execution of the survey. Structured questionnaires together with a combination of intensive interviews consisting of semi-structured questionnaires were administered in focused group discussion (FGD) with surrounding dwellers, daily laborers; and, experts that were randomly selected from each selected sugar factories. To supplement the primary data, secondary data were also collected from the factories clinical data and surrounding groups.

The respondents were from daily labor (sugarcane cutter), animal breading farmers and expertise discussions from factory agricultural operation, harvest team, camp households, sugarcane out-growers, sugarcane cutters, and associations and unions, key informants and other group representatives. Accordingly, all impacts of harvesting of green sugar cane use were listed and evaluated. Some were estimated in quantitative terms, while others were evaluated qualitatively. The assessment was conducted using both qualitative and quantitative data.

\section{Data analysis}

In the current study, descriptive statistics methods like proportions and means were used to describe the findings. Statistical software (SPSS version-21) was used to analyze the data.

\section{Results and Discussions}

This section presents the socio economic impact of pre-harvest cane burning practice based on survey and interviews data from sugarcane cutters ${ }^{1}$ and nearby farmers ${ }^{2}$.

\section{Socio-demographics description of samples}

The majority of respondents included (i.e. sugarcane cutters and local farm households) had low level of education. The full sample description is given in Table 1. Their age range was 22 to 75 . Most (89\%) of the respondent farm households are male; this shows that female were not participating in sugarcane cutting process. This may be due to difficulties/hardships of the cutting operations.

The income rage of respondents was between 1,000 Ethiopian birr (ETB) (about $34.30 \mathrm{USD}^{3}$ ) to 15,500 ETB

1 Sugarcane cutters: Respondent sugarcane cutters came from different parts of the country (mostly from southern nation and nationalities of Ethiopia). They participate on this sugarcane cutting activity for the purposes of substance life i.e. for purposes of their daily consumption and family survival. They have been living eight months per year in the sugar factories, and then they go back to their families or their residences. This is a seasonal work. As a result, they get their money only for seven or eight month's per year since the factory closes for yearly maintenance on the remaining months.

2 Nearby households: the nearby households are economically dependent on the factories because they most of them are out grower farmer. The main sources of animals feed in the area are the unburned cane trash (shot) of cane farm after cane burning. The way of obtaining this cane trash for most farmers is collecting and for some of them buying from other collectors.

${ }^{3}$ One Ethiopian birr (1 ETB) is converted to 0.0343 USD (an average exchange rate in 2019) at exchange rate of 29.15 Ethiopian birr for a US 
(about 531.65 USD) with a mean average income of 1,940 ETB (about 66.54 USD). The income analysis indicates high income-disparity among the respondents and the lowest income reported is below the poverty line (45 USD/month) of Ethiopia. Similarly, all respondents have more than one family member.

Table 1: Socio demographics description of sample

\begin{tabular}{lcccc}
\cline { 2 - 5 } \multicolumn{1}{c}{$\quad$ Variable } & Min & Max & Mean & Std. Dev \\
\hline Age (in years) & 22 & 75 & 34.39 & 10.408 \\
Education (years of schooling) & 2 & 4 & 2.46 & .657 \\
Household size (in number) & 1 & 11 & 5.39 & 2.985 \\
Years in sugarcane cutting & 2 & 39 & 12.22 & 9.331 \\
Average income per month (in birr) & 1,000 & 15,500 & 1,940 & 2.077 .4 \\
\hline
\end{tabular}

Source: Computed from survey data, 2019

\section{General view on pre-harvest burning of sugarcane plantation}

First, the respondents (i.e., sugarcane cutters and nearby smallholder farmers) were asked to state on main reasons why the factory plantation burn sugarcane fields before harvest. As shown in Figure 1, the responses described by respondents include; to remove trashes from sugarcane and to cut the sugarcane easily (100\%), to eliminate different poisonous animals like insects/snake $(76 \%)$, to facilitate sugarcane harvesting process and to reduce the amount of extraneous matters sent to the mill $(56 \%)$, and the remaining respondents have no awareness on the idea. This result coincides with that of (Figueiredo and La Scala 2011), who found out that burning of sugarcane fields is practiced to facilitate harvesting by quickly and cheaply removing excess biomass, to reduce dangers from snakes and insects.

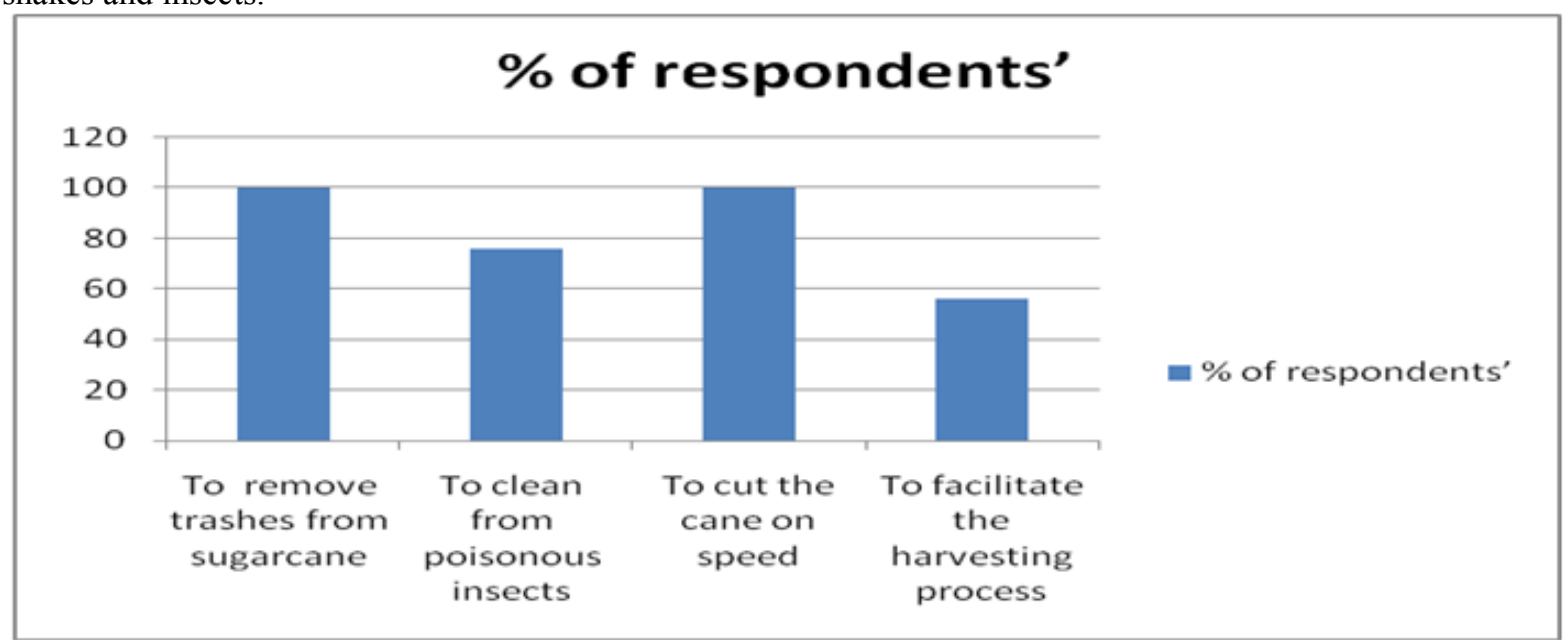

Figure 1: respondent response on the main reasons why sugarcane fields are burned before harvest

The respondents, secondly, were asked about the impacts of pre-harvest burning of sugarcane fields. Almost all respondents agreed on its negative impacts such as impacts on human health, resource degradation and air pollution.

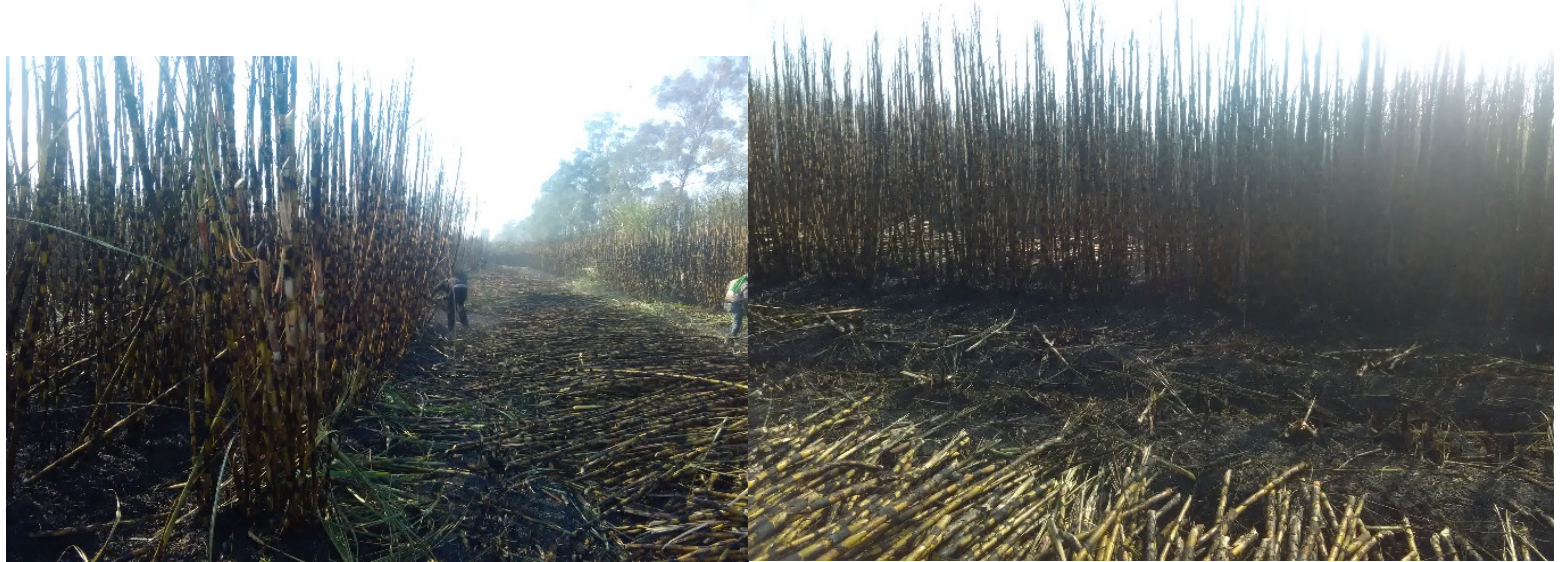

Figure 2: Manual sugarcane harvesting practices of burned fields. 
On the other hand, the respondents were asked if the know others sugarcane harvesting options, their advantages and disadvantages?' All the respondents (100\%) answered yes and consequently proposed the options of green harvesting (either manual or mechanical). They also added their fear as "although the green harvesting practice is more preferable than current harvesting process in reducing environmental burden, it might be expensive and it may totally changes current sugar industry harvesting process facilities." Similarly, the respondents described the advantage of green sugarcane harvesting options in different words. Some said, "Economically- we are capable of utilizing sugarcane trash as animal feeds and creating different job opportunities."Others argued "they would rather use as alternative energy sources and boiler fuel as well as are able to apply for fields that retain and control organic matters when the trash and topping are incorporated to the soils; as a result it increases soil organic matters/soil faun (microbes) such as bacteria and fungi load increase sugarcane productivity. Environmentally, it avoids air pollutants (like fly ash and emission of gases) that adversely affect human health, it contribute for green economy that safe guard for the environment. Concerning about disadvantages of green harvest practice, the majority of respondent explained that this practice is expensive that requires high cost of machinery, difficulty to manage trash on commercial sugarcane fields due to different structures like furrow irrigation system, it affects water movement in furrow irrigation system, it may reduces the current employment opportunities and it may affects water movement in furrow irrigation system and it may harbor pests.

\section{Impacts on socio economy}

Most of respondents (87\%) agreed that pre-harvest burning of sugarcane practice was degraded the biomasses that possibly utilized for others economic options such as using trash as animals' feed and sources of alternative energy. The main socio economic benefits of sugarcane trash ${ }^{1}$ that was identified by respondents (local farmers and sugarcane cutters) were - the majority of respondents (75\%) show that sugarcane trash may be used as part of a ration for animals feed (for both fattening and milking) and are able to use as alternative energy sources. In their responses they indicated that, we could prepare animal feeds ration from trash by organizing them as small and medium scale business enterprises; that improve our livelihoods consequently different job opportunities was created. One of the interviewee reasoned out the issue, as "Currently, I am a Factory employee as causal laborer; however, if the factory adopts green cane harvesting practice; I would happily participate in different small scale business options like processing animal feed from green sugarcane and others related activities.

In addition, the laboratory results show that sugarcane trash (tops and dry/green leaves) has great calorific value (4909.09 Calorie/gm) of energy. This result was also supported by the responses of most respondents and key informant interviewee. They identified sugarcane trash usage as 'an alternative energy/fuel sources like briquette charcoal that reduces environmental burden eventually protecting trees from being harmed for firewood purposes'.

This finding has important implication; when green harvesting practice was applied; on how unemployed local communities, out-grower farmers and others individual around the factory improve their livelihoods from usage of trash biomass for animals feed that create different job opportunities and others related economic activities. Similarly, sugarcane trash usage satisfies individuals' energy needs as alternative energy sources like briquette charcoal that convert wastes into combustible biomass while alleviating landfill use.

On the other hand, the respondents describe when the trash and topping left on the field are incorporated to the soils it could be serving as retaining and controlling organic matters soil faun (microbes such as bacteria and fungi) that improves soil physic chemical properties eventually increases sugarcane productivity and soil health. This was confirmed by other studies trash farming minimizes the artificial fertilizer; protect soil salinity and increasing soil fertility by motivating decomposition (Anonymous, 1994, and Thorburn et al., 2001).

\footnotetext{
${ }^{1}$ Sugarcane trash is a leftover in the sugarcane fields (that consists green and dry leaves, tops and fractions of stems, roots and soil particles attached to them) after harvesting. This is common particularly in the case of mechanical harvesting.
} 


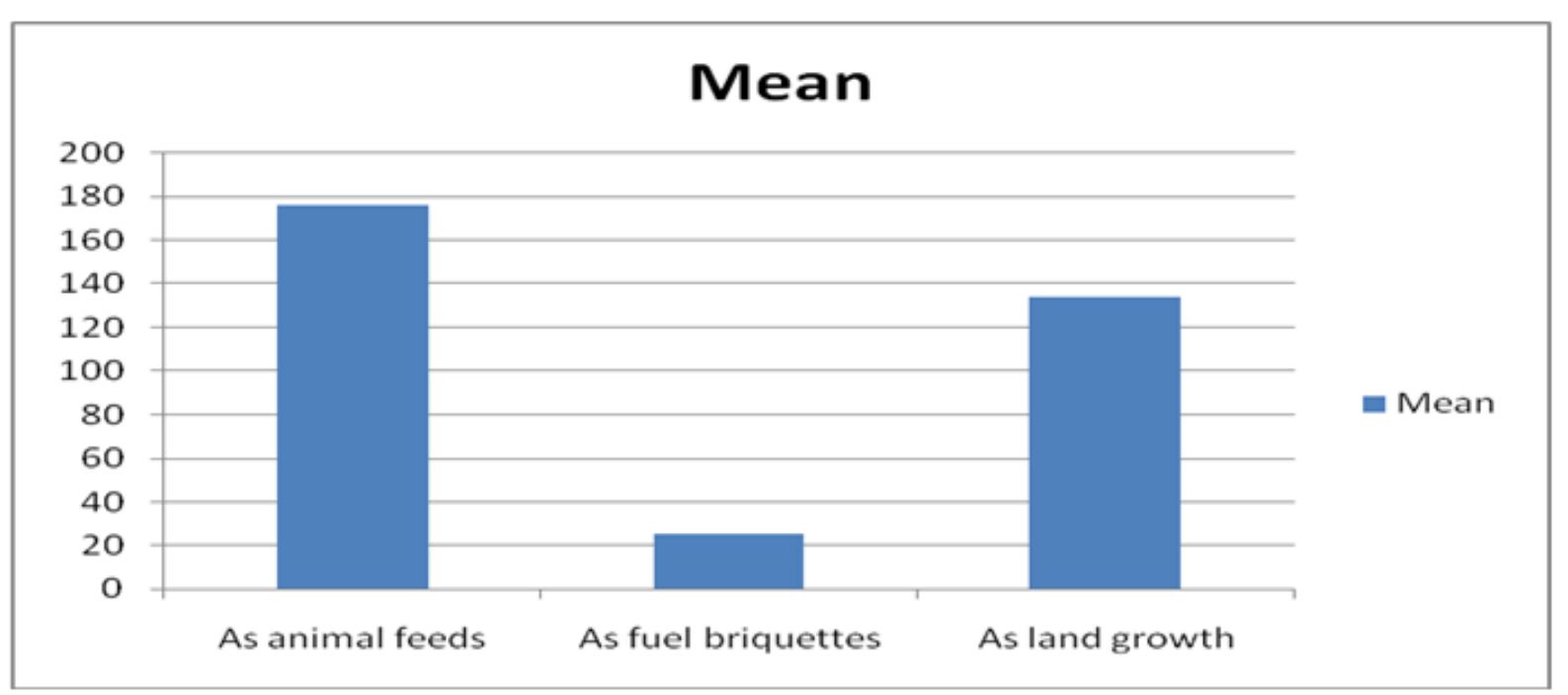

Figure 4: The nearby community (responses) that uses of trash

The responses of respondent of the benefits of green cane harvesting with Likert-scale rates was presented in the following figure.

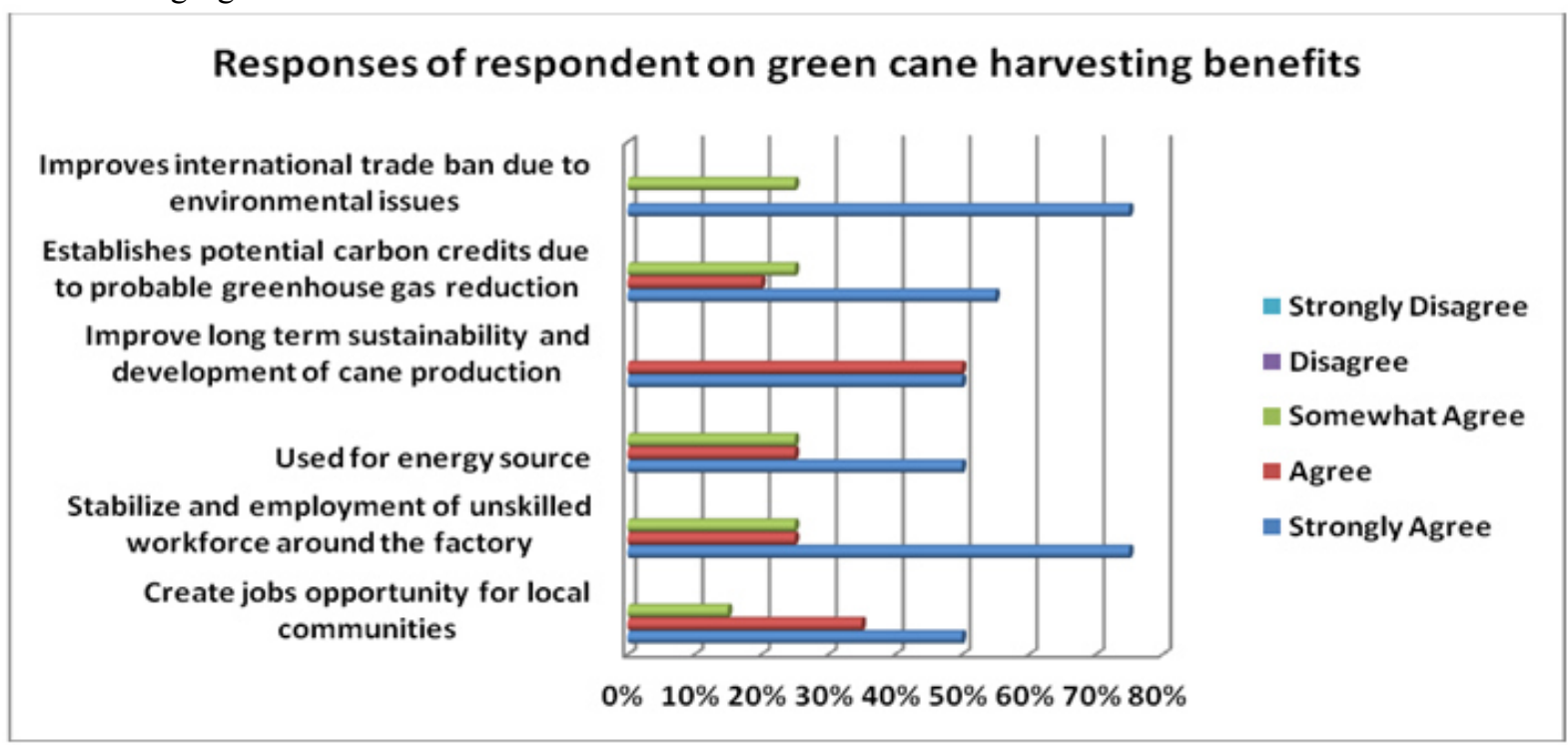

\section{Impacts on human health}

All $(100 \%)$ of the respondents opinioned that pre-harvest sugarcane burning have the problem on human health. This result was similar to that of Mitchell et al, 2000; even though pre-harvest burning process was used to facilitate the harvesting process; it pollutes the environment that adversely affects human health and lost most of the organic matter and nutrients in the trash.

According to responses of respondents, various physical as well as medical problems occurred due to these practices. To summarize some of them: - sugarcane cutters were injured during harvesting time because of accidents; human health problems like respiratory illness, eye illness (like trauma, accidental blooding and others eye health problem) due to foreign body or dust, and asthma-related illness (cold, and others health problems) due to bad smell of deposited black ash/smoke particle/dust sedimentation in living areas. They give description as the released cane ash can easily enter to their eyes as well as the ash and smoke inhalation as a result their eyes and others parts could cause health risks. This result was also supported by responses of health worker discussions at factory Hospitals. 


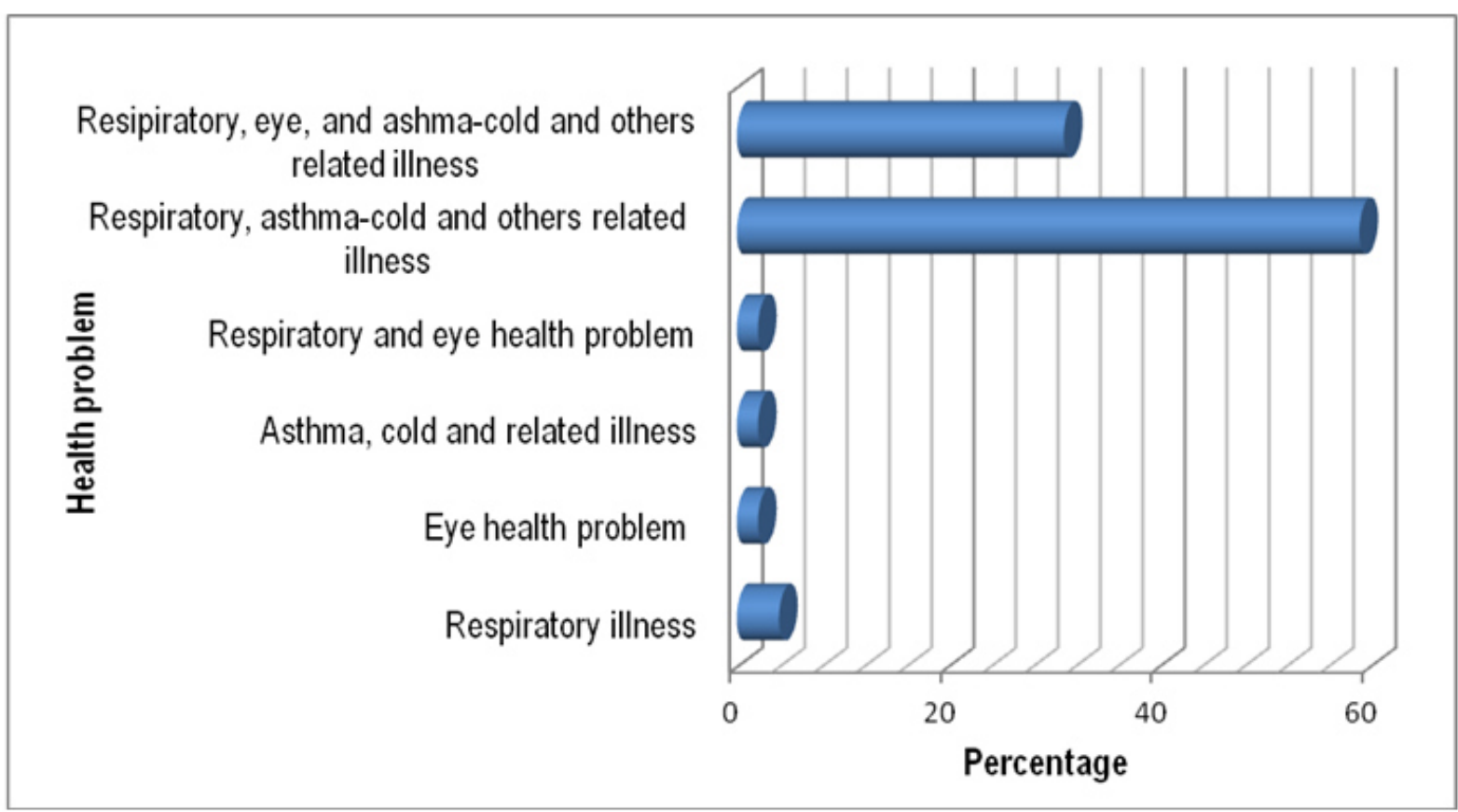

Figure 3 the main health therapy visits in two Hospital and three Clinics within one Year (for cane cutters)

As shown in Figure 4, More than half (59\%) of the respondents' health was affected. They said, "due to burning practice, sugarcane cutters and surrounding communities were suffering from respiratory problems like asthma, cold and similar health defects. According to their responses, this is due to bad smells of deposited black ash/smoke; and particle/dust sedimentation in their living areas and it has become the continued major health problems in factories. Similarly, 30\% of cane cutter respondent indicated that the health consequences of the preharvest cane burning in area were the respiratory health problem, eye illness (eye health problem (like trauma) due to foreign dust, and asthma, cold and others health problems due to bad smell of deposited black ash/smoke particle/dust sedimentation in living areas. In addition, this is supported by the responses of nearby farmers respondent; most $(83.7 \%)$ of nearby farmers respondent have awareness of pre-harvest burning of cane on environmental and health impacts.

Similarly, the responses from in-depth interview were agreed on human health and environmental impacts. The data collected from two hospitals and three clinics showed respiratory and others related health problems increased during sugarcane burning time than off-season. It is clear that, the burning of sugarcane generates a massive quantity of smoke that spread in the environment and becoming a potential threat to the human health.

\section{Impacts on environment}

Many Respondents pointed out that sugarcane trash (tops and dry/green leaves) that is usually burnt for harvest is reducing the excessive mulching on the sugarcane farm. This practice does not allow proper sugarcane growth after harvest. This result was supported by the finding of Caldeira (2002) that pointed out the positive aspects to the soil, in terms of erosion control, moisture retention, improved biological, chemical and physical properties arising from decomposition of crop residues on the soil surface. Hassuani et al. (2005) also recommended that about half of the trash be kept on the ground to reduce erosion, recycle nutrients and maintaining a minimum level of moisture in the soil. Similarly, most of the respondents' $(75 \%)$ responses revealed that the practice of burning sugarcane prior to harvest creates air pollution by releasing of fly ash to the environment that affects health the community.

\section{Conclusion}

The present study presented an analysis of socioeconomic and environmental impacts resulting from pre-harvest burning of sugarcane at Wonji/Shoa and Metahara sugarcane estates. Data was collected through household interviews, key informant interviews, focus group discussions, direct observation and field notes of the researcher as well as secondary data from various sources to complement the primary data

All respondents $(100 \%)$ confirmed that pre-harvest sugarcane burning practice have negative impacts on local economy in terms of human health (both local communities and sugarcane workers) resulting from smokes and dust particles. Similarly, most of the respondent (75\%) responses revealed that the practice of burning sugarcane prior to harvest creates air pollution by releasing of fly ash to the environment that affects health the community. On the other hand, the finding from the majority of respondents (75\%) show that trash of sugarcane can be regarded 
as an asset (this includes usage of sugarcane trash resources as part of a ration for animals' feed both for fattening and milking) and others alternative energy sources like briquette charcoal and soil compost) rather than extraneous matters and have a host of alternatives uses. The result of the findings will help to guide sugar industries and policy makers with new insights/ strategies in understanding the situated environmental and social impacts associated with alternative sugarcane harvesting system (like green harvesting technologies either manual or mechanical), opening job opportunity to the local communities, out-grower farmers and others individuals by utilization of trash as animals feed, energy source and compost.

Based on the finding of this study, (i) the inclusion of domestic legislation of environmental issues at sugar industry that introduces legal control as a guarantee for compliance with the standards provided for in each case are essential conditions to minimize socioeconomic impacts of pre-harvest burning of sugarcane plantation (ii) formulation and implementation of policy intervention should address these problem by introducing green harvest practice that reduce the air pollution, create diversified economic activities to local and out-grower farmers (such as producing/processing animal feeds, producing alternative energy source from sugarcane trash like briquettes charcoal) (iii) the sugar industry should take the necessary polices measures aimed at correcting the failure to improve the health of the population by eliminating the practice of burning sugarcane prior to harvest.

\section{Acknowledgments}

The authors are grateful to Research \& Development Main Center at Ethiopian Sugar Corporation and Ethiopian Environment \& Forest Research Institute at Central Ethiopia Research Center for support and granting permission to undertake this research study. Special thanks go to all who assisted during data collection and the respondents who gave valuable data without which the study would not have happened.

\section{References}

Anonymous, 1999. Crop production-Sugarcane. Proceedings of Annual Review Workshop Meeting, Zonal Agriculture Research Station, VC Farm, Mandy

Caldeira, D. S. A., 2002. Palhiço residual de cana-de-açú- car (Saccharum spp.) colhida mecanicamente (sem queima prévia): manejo, fertilização, influência no perfilhamento e produtividade da cultura

Cançado, J.E.D., Saldiva, P.H.N., Pereira, L.A.A., Lara, L.B.L.S., Artaxo, P., Martinelli, L.A., Arbex, M.A., Zanobetti, A., Braga, A.L.F., 2006. The impact of sugar cane burning emissions on the respiratory system of children and the elderly. Environ. Health Persp. 114 (5), 725-729.

Figueiredo, E.B., La Scala Jr., N., 2011. Greenhouse gas balance due to the conversion of sugarcane areas from burned to green harvest in Brazil. Agriculture. Ecosyst. Environ. 141 (1e2), 77-85.

Hasuani, S. J.; Verde Leal, M. R. L.; Macedo, I. C., 2005. Biomass power generation: sugarcane bagasse and trash. Project BRA/96/G31 PNUD - CTC. Piracicaba: Unipress Disc Records do Brasil, Série Casminhos para Sustentabilidade

Leite MR, Zanetta DMT, Trevisan IB, Burdmann EA, Santos UP., 2018. Sugarcane cutting work, risks, and health effects: a literature review. Rev Saude Publica, 52; 80. http://dx.doi.org/10.11606/s15188787.2018052000138

Marcos A. Arbex , Gyorgy M. Böhm, Paulo H.N. Saldiva, Gleice M.S. Conceição , Arden C. Pope III \& Alfesio L.F. Braga, 2000. Assessment of the Effects of Sugar Cane Plantation Burning on Daily Counts of Inhalation Therapy, Journal of the Air \& Waste Management Association, 50:10, 1745-1749, DOI: https://doi.org/10.1080/10473289.2000.10464211

Mitchell RDJ, Thorburn PJ, Larsen P., 2000. Quantifying the loss of nutrients from the immediate area when sugarcane residues are burnt. Proceedings of the Australian Society of Sugar Cane Technologists 22: 206211.

Ribeiro, H., 2008. Sugar cane burning in Brazil: respiratory health effects. Rev. Saúde Pública 42 (2)

Thorburn PJ, Robertson FA, Lisson SN, Biggs JS, 2001. Modeling decomposition of sugarcane surface residues and the impact on simulated yields. In: 'Sustainable Management of Soil Organic Matter 74-82. 